\title{
ABAG: Origens históricas e consolidação hegemônica
}

\section{ABAG: Historical origins and hegemonical consolidation}

Sonia Regina de Mendonça - Doutorado em História Econômica pela USP, docente do Programa de Pós-Graduação em História da Universidade Federal Fluminense (UFF) e pesquisadora 1 do CNPq, atuando na área de História Política da Agricultura. E-mail: srmendonca@uol.com.br

Pedro C. F. Oliveira - Doutorando do Programa de Pós-Graduação em História da UFF e bolsista do CNPq. E-mail: pcfo@hotmail.com

\section{Resumo}

O trabalho, fruto de pesquisa em andamento, analisa o processo de consolidação da hegemonia de um novo segmento dos grupos agroindustriais brasileiros ocorrido entre as décadas de 1990 e 2000, articulado pela Organização das Cooperativas Brasileiras (OCB) e coroado pela fundação da Associação Brasileira de Agronegócio (ABAG). Com base em documentos oficiais, bem como aqueles produzidos por esta última, refletimos sobre os projetos elaborados por dirigentes da ABAG, enfatizando a metodologia de mapeamento destes últimos, com o objetivo de demonstrar seu grau de inserção junto a organismos da sociedade política, no período compreendido entre 1993 e 2013.

\section{Abstract}

The paper, which comes from a research in its beginning, analyses the process of hegemonic consolidation of a new group of Brazilian agroindustrial entrepreneurs during the decades of 1990 and 2000, articulated by the Brazilian Cooperatives Organization (OCB) and crowned by Brazilian Agribusiness Association foundation (ABAG). Based on official data, as well as on those produced by the latter, we reflect about the projects elaborated by the Association leaderships, empathizing the methodology of their mapping, aiming to demonstrate the degree of their insertion in the political society agencies, during the period from 1993 to 2013.

\section{Palavras-chave}

Agronegócio.

Organização

das

Cooperativas Brasileiras. Associação Brasileira do Agronegócio. Estado Restrito. Hegemonia.

\section{Keywords}

Agribusiness. Brazilian Cooperative Organization. Brazilian Agribusiness Association. Restrict State. Hegemony. 


\section{A ABAG: ORIGENS}

A direção exercida pela OCB junto ao conjunto de entidades patronais da agroindústria consolidou-se na virada dos anos 1980 para os 1990, contando com um significativo "gran finale": a proposta de criação de uma nova entidade - a Associação Brasileira de Agronegócio (ABAG) - em teoria seria responsável pela articulação/integração de todas as demais. O eixo articulador da proposição, enunciada pelo então presidente da OCB, Roberto Rodrigues, residiria na necessidade de afirmação política do então chamado agribusiness no país. Segundo a revista da agremiação,

Foi dessas viagens que surgiu um conjunto de ideias que, aliadas a sua [de Roberto Rodrigues] experiência como representante da agricultura no Conselho Monetário Nacional, membro do Conselho Nacional de Política Agrícola e Coordenador da Comissão Empresarial de Competitividade do Ministério da Economia, resultou no trabalho apresentado, que será um ponto de partida para o debate junto à classe rural do "agribusiness" brasileiro (Informativo OCB, nov., 1991, p. 34).

Em maio de 1993 nasceria a ABAG, presidida por um dos diretores da OCB, Ney Bittencourt de Araújo, também dirigente da Sociedade Nacional de Agricultura (SNA) e da Sociedade Rural Brasileira (SRB), legitimado por sua própria trajetória, de todo compatível com o perfil da nova entidade. Mineiro, agrônomo, diretor da Sementes Agroceres S.A., da Sementes Horticeres S.A. e da Agroceres Importação e Exportação, Comércio e Indústria S.A., membro da Associação Paulista de Engenheiros Agrônomos, da Sociedade Brasileira de Agronomia, da Sociedade Brasileira de Olericultura e da Sociedade Brasileira de Defensivos para Agropecuária, além de ter sido presidente da Associação Brasileira dos Produtores de Sementes e Mudas (ABRASEM), Bittencourt seria copartícipe do legado de Rodrigues, incumbido de levar à prática o mais importante instrumento de consagração da $\mathrm{OCB}$ como força social hegemônica (GRAMSCI, 2000, v. 3).

A fundação da $A B A G$ teria como justificativa para sua implantação dois argumentos fulcrais. De um lado, a constatação - ou construção ideológica? - de que já existia no país uma "nova agricultura", distinta daquela até então em vigor, posto que "desenvolveu-se a agroindústria, que passa à liderança do processo produtivo e consolidam-se as grandes cooperativas, dando origem a um novo sistema" (ARAÚJO, 1994, p. 3, grifo na fonte). De outro, como extensão "natural" da primeira impunha-se a imperiosa necessidade de estabelecerem-se novos canais da representação política setorial, à altura de sua relevância econômica. No 
primeiro caso, desenvolveu-se todo um trabalho de direção ideológica destinado a fazer convergir para a agricultura o conjunto das atividades econômicas do país, passando ela a ser tida como "a atividade principal" posto que respaldara "galhardamente" a economia brasileira ao longo da crise vigente desde inícios da década de 1980. Em face dessa evidência e numa operação simbólico-política da maior envergadura, a OCB promoveria a "recriação" do próprio conceito de agricultura, imbricando-a à noção, bem mais ampla, de agribussines", não mais limitado à atividade agrícola tout cours, porém referida a um brutal processo de tecnificação e financeirização do mundo rural, responsável pela emergência de

um novo segmento antes da porteira da fazenda, o da pesquisa e experimentação, que passaram a ser exigências fundamentais através da produção de sementes melhoradas, corretivos e fertilizantes; tratores, defensivos, vacinas, rações e medicamentos Surgiram ainda mecanismos especializados de credito, para custeio e investimento e apareceram ações de marketing no campo (ARAÚJO; PINAZZA, 1994, p. 35).

Contudo, o aludido "novo segmento" não era assim tão recente quanto se pretendia fazer ver e fazer crer (BOURDIEU, 1989, p. 7-15) tendo-se originado da "modernização" da agricultura ocorrida nos anos 1970, conquanto não tão explicitamente associado ao capital financeiro como agora. Se alguma novidade existia, consistiu na fundação de uma entidade que passou a integrar, num único sistema, todas as atividades definidas como correlatas ao "agrário". Todavia, a noção de agribusiness atrelada à ideia de interdependência inter-setorial, não estaria completa caso vinculada, tão somente, ao chamado "mundo anterior à porteira", pois este só se justificava e se instituía em razão da existência de

um segmento ainda maior, depois da porteira da fazenda: armazenamento, transporte, processamento e embalagem, industrialização, distribuição de produtos [...]. O agricultor passou a ser um especialista em plantar e criar, em intima interdependência com os segmentos a montante e a jusante da fazenda" (ARAÚJO; PINAZZA, op. cit., p. 120, grifos nossos).

Quanto ao segundo ponto mencionado, é fundamental ratificar que a noção de agribusiness organizaria e instrumentalizaria a imbricação de todas as atividades econômicas direta ou indiretamente à agricultura - agora resignificada como a "mera especialização em plantar e criar" - dando origem a um poderoso complexo de cunho comercial-financeiro, cuja importância não se aquilataria apenas a partir de seu desempenho econômico, porém, sobretudo, por sua influência política. Não é difícil perceber que a agricultura tornava-se avalista de um sistema produtivo mais amplo e complexo, em função do qual urgia criar 
uma mega-agremiação, supra associativa e correspondente, no plano político, a seu "peso econômico" ainda que, nas palavras de seus idealizadores, "nenhuma das entidades pré-existentes fosse desaparecer", pois “a ABAG não nasce para substituir as associações dos vários segmentos que a constituem, todas elas participantes de seu conselho Consultivo” (Idem, p. 141, grifos na fonte).

\section{A ABAG: LEGITIMAÇÃO}

A fundação da $A B A G$ seria legitimada como uma reação do empresariado agroindustrial à "incompetência" das agências estatais no enfrentamento da crise econômica em geral e da agricultura, em particular. A “miopia” por ele atribuída ao Estado restrito respondeu pela estagnação das atividades agroindustriais, devendose transferir, para as entidades patronais, a responsabilidade pela busca de soluções para os problemas enfrentados. Afinal, "o Agribusiness brasileiro existe e já está consolidado desde a década de 1970. Ele é o maior negócio do país, representa quase $40 \%$ do PIB, metade dos empregos, 46\% do dispêndio das famílias, $40 \%$ das exportações e 60\% da balança comercial” (ARAÚJO, 1994, p. 2, grifos nossos).

O site oficial da ABAG em suas origens apresentava, dentre suas "tarefas e missões", aquela de

[...] conscientizar os segmentos decisórios do país - os políticos, os empresários, os trabalhadores organizados, os acadêmicos, os líderes de comunicação - para a importância e complexidade da cadeia do agribusiness, a relevância de seu papel no desenvolvimento econômico e social e a necessidade de tratá-lo sistematicamente, sem o que se torna impossível otimizá-lo; [...] a de tornar o agribusiness ciente e entendido, já que a falta do conhecimento mais elementar de seu funcionamento e dos seus elementos mais importantes, eclipsa a visão de conjunto e as importantes interações que ocorrem dentro do sistema" (www.abag.org acesso em 20-11-2004, grifos nossos).

A grande imprensa igualmente se envolveu na promoção da entidade emergente, através de matérias francamente elogiosas e com forte apelo à opinião pública:

AGROINDÚSTRIA TEM ENTIDADE DE NÍVEL NACIONAL: ABAG - Reunidos sob uma mesma entidade, $40 \%$ do PIB brasileiro, no auditório Nereu Ramos, da Câmara dos Deputados, foi lançada nacionalmente, a Associação Brasileira de Agrobusiness, que surge para representar e articular as ações de empresas vinculadas ao complexo agro-industrial, reunindo desde cooperativas até frigoríficos exportadores. O peso pesado da nova entidade congregará a Agroceres, Maxion, Sambra, Cobram e Febraban e, como não poderia deixar de ser, sua sede nacional será em São Paulo (CORREIO BRAZILIENSE, 5-5-1993, p. 9, grifos nossos). 
Como se percebe, a ABAG consistiu muito mais numa agremiação de empresas do que de entidades patronais propriamente ditas, inaugurando uma modalidade associativa de novo tipo no país. Apesar disso, o mesmo jornal insistiria em afirmar, como o fizeram os dirigentes da associação que

[...] a nova entidade não se superpõe às diversas organizações representativas de segmentos do setor agroindustrial. Ela tem, em sua definição, uma função macro, não se constituindo em órgão de lobby setorial e visa desenvolver um trabalho de doutrinação sobre a importância da atividade agroindustrial para a sociedade" (CORREIO BRAZILIENSE, 6-5-1993, p. 14, grifos nossos).

Insistindo em caracterizar a ABAG como órgão apolítico, o periódico enfatizava sua função "técnica", justificada pelo fato de ampliar a competitividade estrutural e setorial, uma vez que, até então,

o setor de 'negócios agrícolas' vinha atuando em segmentos distintos, máquinas e implementos, adubos e defensivos e outros, não buscando soluções para resolver os problemas comuns [...]. Porém o empresariado se deu conta da necessidade de globalizar as estratégias para ter resultados mais rápidos" (CORREIO BRAZILIENSE, 9-5-1993, p. 17, grifo nosso).

Todavia, o cunho político da nova agremiação era evidente. Segundo matéria publicada em O Estado de São Paulo,

Criada pelos principais grupos econômicos do setor agrícola, a ABAG é o principal instrumento para tornar viáveis as metas do setor. Esses grupos estão convencidos de sua capacidade de influir na revisão constitucional em favor do que chamam de Revolução do setor agrícola. A ABAG é a nova força do setor" (OESP, 7-5-1993, p. 2, grifos no original).

O discurso de posse de seu primeiro presidente, Ney B. Araújo, ratificou os pontos axiais de atuação da entidade, destacando que "o desenvolvimento sustentado do Brasil começa pela segurança alimentar e pelo fortalecimento da cadeia de alimentos e fibras e, por isso, a OCB e lideranças do sistema decidiram fundar a Associação Brasileira de Agribusiness" (ARAÚJO, 1994, p. 1, grifos nossos).

Como se percebe, os dirigentes da ABAG extraíram sua legitimidade de duas noções fortemente imbricadas à retórica neoliberal dos anos 1990: Segurança Alimentar e Competitividade. Conquanto fossem "incompatíveis", os intelectuais orgânicos da agremiação rapidamente trataram de compatibilizá-las imputando ao agribusiness brasileiro o papel de coadjuvante essencial da Segurança Alimentar mundial. Por tal mecanismo ideológico, despia-se o agronegócio de 
seu caráter plenamente capitalista e transnacional, integrado por uma cadeia empresarial de forte cunho comercial, industrial e financeiro. Tal como já analisado em relação ao Cooperativismo (MENDONÇA, 2010) cuja entidade máxima (OCB) lhe dera origem, também se verifica, no caso da ABAG, a mesma operação simbólica de "transmutação" de seu ethos empresarial em "missão social" 1. A "responsabilidade social" dos empresários do agribusiness para com a sustentação alimentar de uma comunidade internacional altamente "globalizada" foi o grande instrumento de produção do consenso nacional em torno a seu projeto.

Em matéria de segurança alimentar, o Brasil tem um papel a cumprir. É o $4^{\circ}$ exportador de produtos do agribusiness mundial e tem a $6^{\text {a }}$ população mais mal nutrida do planeta. Acima de uma política agrícola o que está se discutindo é a urgência e o compromisso com uma política de alimentos. O desenvolvimento rural e o aumento de produtividade jamais ocorrerão se não estiverem inseridos no contexto de uma bemsucedida estratégia global, dotada de alta competitividade” (ARAÚJO; WEDEKIN; PINAZZA, 1990, p. 87, grifos nossos).

Ao mesmo tempo, a citação explicita a grande contradição embutida na autojustificativa do conceito de agronegócio e sua "missão". Encontramo-nos diante de uma cadeia de atividades econômicas altamente empresarializadas e financeirizadas, cujo produto final destina-se, prioritariamente, à exportação, mormente no contexto histórico de início do processo de desindustrialização brasileira (MENDONÇA, 2004), marcado pela abertura externa da economia do país, que detinha a sexta população mais mal alimentada do mundo! A despeito disso, os dirigentes da nova entidade iriam ainda mais longe na explicitação de seu projeto para a "agricultura brasileira", ao definirem seus parâmetros norteadores:

A competitividade exige harmonização de vários componentes, mas dois são essenciais: tecnologia e gestão. O centro do poder migrou para a capacitação cientifica e tecnológica, centrada na informação e em novas técnicas de gestão (ARAÚJO; PINAZZA, op. cit., p. 116, grifos no original).

Ora, tal projeto guarda bem pouca afinidade com o mercado interno e menos ainda para com os destinos da população brasileira, embora se tenha insistido em "vesti-lo" do estratégico papel de compatibilizador entre

Segundo Araújo, “a ABAG nasce de uma visão e de uma missão. A visão é a de que a vocação, a capacitação e os recursos brasileiros no agribusiness podem se adequadamente administrados, contribuir de forma decisiva para vencer os grandes desafios da sociedade brasileira [...]. A missão, penosa, ambiciosa e difícil, é sistêmica e se encadeia em múltiplas tarefas. A primeira e maior delas é de conscientizar os segmentos formadores de opinião e decisórios do país - políticos, empresários, sindicatos, acadêmicos, lideres de comunicação - para a importância do sistema do agribusiness". (ARAÚJO, 1994: 7, grifo no original. 
"desenvolvimento econômico" e "bem-estar social". O peso político do novo setor, assim "reinventado", deveria corresponder ao papel por ele detido junto à geração da riqueza nacional. Para tanto, a ambição política dos dirigentes da ABAG consistia em

Juntar suas forças às demais instituições brasileiras neste momento em que se discute a Reforma Constitucional e participar ativamente na grande discussão nacional de redefinir o Estado. [...]. E o agribusiness não se coordena sem intima parceria como Estado. Há, pois uma tarefa política para a ABAG, a de transformar-se em importante ferramenta de apoio ao planejamento estatal do agribusiness brasileiro" (Idem, p. 6, grifos nossos).

\section{A ABAG: COMPOSIÇÃO}

O site oficial da ABAG destacava, dentre seus objetivos e ações já no ano de 2005, o de firmar parcerias com ministérios e agências do Estado - CNPq, FINEP, DENACOOP etc. - para promover a evolução da política agrícola e alimentar; participar das gestões preparatórias de negociações com organismos normativos do agribusiness internacional (como a Organização Mundial do Comércio ou a Cúpula Mundial de Alimentação); aproximar-se de agências oficiais de fomento econômico de vários países, visando atrair investimentos e integração tecnológica; participar de fóruns e câmaras que integrassem os programas estatais destinados ao aumento das exportações, além de programas educativos ou de desenvolvimento profissional, em conjunto com entidades setoriais como a SRB, a Associação Nacional para a Difusão de Adubos (ANDA), a Associação Nacional de Defesa Vegetal (ANDEF), a Associação Brasileira de Marketing Rural (ABMR), dentre outras. Agremiações como a SNA que, desde 1985, haviam redirecionado sua linha de ação no rumo das atividades de cunho ambiental e educacional, foram excluídas da nova entidade "patronal".

Apenas a título de comparação, elaboramos o Quadro 1, elencando as "entidades patronais" que constam como associadas da ABAG, em 2003 e em 2013.

\footnotetext{
2 "Um modelo de desenvolvimento que, pela competitividade econômica e importância social, priorize a cadeia de alimentos e fibras, deve prover estratégias que dissolvam o conflito entre o desenvolvimento econômico a médio e longo prazos e os problemas críticos do bem-estar social, em curto prazo. Uma política de segurança alimentar sólida pode ser este solvente" (ARAÚJO; WEDEKIN; PINAZZA, 1990, p. 23).
} 
Quadro 1 - ABAG: associados (2003 e 2013)

\begin{tabular}{|c|c|}
\hline 2003 & 2013 \\
\hline 1 AGCO do Brasil & Adeco Agropecuária Brasil S/A (*) \\
\hline 2 Agência o Estado (OESP); & ADM do Brasil Ltda. $(*)$ \\
\hline 3 Agroceres Nutrição Animal Ltda & AGCO do Brasil \\
\hline 4 Algar S.A. Empreendimentos e Participações & Agrifirma Brasil Agropecuária S/A $(*)$ \\
\hline 5 Arthur D. Little Ltda & Agroceres Nutrição Animal Ltda \\
\hline 6 Associação Brasileira da Batata (ABBA); & Agroconsult Consultoria e Projetos Ltda. $(*)$ \\
\hline $\begin{array}{l}7 \text { Associação Nacional de Defesa Vegetal } \\
\text {-ANDEF }\end{array}$ & Agropalma S/A (*) \\
\hline \begin{tabular}{lllll|}
8 & Banco Cooperativo do & Brasil & S.A. & - \\
BANCOOB & & & & \\
\end{tabular} & Algar S.A. Empreendimentos e Participações \\
\hline 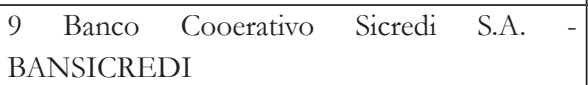 & Aprosoja Brasil (*) \\
\hline 10 Banco do Brasil S.A. & $\begin{array}{l}\text { Associação Brasileira dos Criadores de Zebu - } \\
\mathrm{ABCZ}^{(*)}\end{array}$ \\
\hline 11 Bayer Cropscience Ltda & $\begin{array}{l}\text { Associação Nacional de Defesa Vegetal - } \\
\text { ANDEF }\end{array}$ \\
\hline 12 Bolsa de Mercadorias e Futuros - BM\&F & $\begin{array}{l}\text { Assoc. Nacion. Export. Sucos Cítricos - } \\
\text { CitrusBR }(*)\end{array}$ \\
\hline 13 Bunge Alimentos S.A & Banco Cooperativo Sicredi S/A \\
\hline 14 Bunge Fertilizantes S.A. & Banco do Brasil S/A \\
\hline 15 Caramuru Alimentos S.A. & Banco Itaú BBA S/A $(*)$ \\
\hline 16 Ceres Consultoria S/C. Ltda & Banco Rabobank International Brasil S/A $\left(^{*}\right)$ \\
\hline $\begin{array}{l}17 \text { Consult., Métodos, Asses. e Mercantil Ltda } \\
\text { (CMA) }\end{array}$ & Banco Santander S/A $(*)$ \\
\hline 18 CNH Latin America Ltda & Basf S/A (*) \\
\hline 19 Cia de Tecidos Norte de Minas (Coteminas) & Bayer S/A \\
\hline 20 Cooperativa Agropecuária de Araxá (Capal) & BM\&F Bovespa S/A \\
\hline $\begin{array}{l}21 \text { Cooperat. Agropecuária Cascavel Ltda } \\
\text { (Coopavel) }\end{array}$ & BRF S/A $(*)$ \\
\hline $\begin{array}{l}22 \text { Cooperat. Agricultores Região de Orlândia } \\
\text { (Carol) }\end{array}$ & Brascan Agri S/A $(*)$ \\
\hline $\begin{array}{l}23 \text { Cooperat. Cafeicult. e Agropec. Maringá } \\
\text { Ltda. (Cocamar) }\end{array}$ & $\begin{array}{l}\text { Brasilagro Cia Brasileira de Propriedades } \\
\text { Agrícolas (*) }\end{array}$ \\
\hline 24 Copersucar & Caixa Econômica Federal $(*)$ \\
\hline $\begin{array}{l}25 \text { Cooperat. Mista Prod. Rurais do So Goiano } \\
\text { Ltda. (Comigo) }\end{array}$ & Caramuru Alimentos S/A \\
\hline $\begin{array}{l}26 \text { Cooperat. Reg. Cafeicultores de Guaxupé } \\
\text { Ltda. (Cooxupé) }\end{array}$ & Cargill Agrícola S/A $\left(^{*}\right)$ \\
\hline $\begin{array}{l}27 \text { Cooperat. Tritícola Mista Alto Jacuí Ltda. } \\
\text { (Cotrijal) }\end{array}$ & Ceres Consultoria S/C Ltda \\
\hline 28 Du Pont do Brasil S.A & $\begin{array}{l}\text { Cetip S/A - Balcão Organizado de Ativos e } \\
\text { Derivativo }(*)\end{array}$ \\
\hline 29 EMBRAPA & CGG Trading S/A $(*)$ \\
\hline 30 Fecoagro/Fecotrigo & CHS do Brasil Grãos e Fertilizantes Ltda. $(*)$ \\
\hline 31 Fertibrás S.A. & $\begin{array}{l}\text { CMA Consultoria, Métodos e Assessoria } \\
\text { Mercantil S/A }\end{array}$ \\
\hline
\end{tabular}




\begin{tabular}{|c|c|}
\hline 32 FMC Química do Brasil Ltda. & CNH Latin América Ltda. \\
\hline $\begin{array}{l}33 \text { Fundação Estudos Agrários Luiz de Queiroz } \\
\text { (Fealq) }\end{array}$ & \begin{tabular}{|l|} 
Cocamar Cooperativa Agroindustrial \\
\end{tabular} \\
\hline 34 Grupo Kepler Weber & \begin{tabular}{|llll}
$\begin{array}{l}\text { Companhia de Tecidos Norte de Minas } \\
\text { (Coteminas) }\end{array}$ & \\
\end{tabular} \\
\hline 35 John Deere Brasil S.A. & Coopavel Cooperativa Agroindustrial \\
\hline 36 Maeda S/A. - Agroindustrial & $\begin{array}{l}\text { Cooperat, Agroind. Prod. Rurais So Goiano } \\
\text { (Comigo) }\end{array}$ \\
\hline 37 Malteria do Vale S.A. & Cooperativa Agropecuária de Araxá (Capal) \\
\hline 38 Máquinas Agrícolas Jacto S.A. & Cooperativa Agropecuária e Industrial (Cotrijal) \\
\hline $\begin{array}{l}39 \text { Marchesan Implementos e Máquinas Agr. } \\
\text { Tatu SA }\end{array}$ & $\begin{array}{l}\text { Cooperat. Regional Cafeic. Guaxupé Ltda. } \\
\text { (Cooxupé) }\end{array}$ \\
\hline 40 Monsanto do Brasil Ltda. & Demarest \& Almeida Advogados $(*)$ \\
\hline 41 MRS Logística S.A. & Dow AgroSciences Industrial Ltda. $\left(^{*}\right)$ \\
\hline $\begin{array}{l}42 \text { Organização das Cooperativas Brasileiras } \\
\text { (OCB) }\end{array}$ & Du Pont do Brasil S/A \\
\hline 43 Pioneer Sementes & EMBRAPA \\
\hline 44 Pirelli Pneus S.A. & Evonik Degussa Brasil Ltda $(*)$. \\
\hline 45 Rutherford Trading S.A. & Fecoagro/Fecotrigo \\
\hline 46 Sadia S.A. & FMC Agricultural Solutions \\
\hline 47 Seara Alimentos S.A & Gaia Agro Securitizadora S/A $(*)$ \\
\hline $\begin{array}{l}48 \text { Sindic. Indúst. do Fumo no Estado RS } \\
\text { (Sindifumo) }\end{array}$ & Globo Comunicação e Participações S/A \\
\hline $\begin{array}{l}49 \text { Sind. Nac. Indústria Defensivos Agrícol. } \\
\text { (Sindag) }\end{array}$ & Guarani S/A - Usina Cruz Alta $(*)$ \\
\hline 50 Sipcam Agro S.A. & $\begin{array}{l}\text { Instit. Nac. Processamento Embalagens Vazias } \\
(\operatorname{InpEV})(*)\end{array}$ \\
\hline 51 Sucos Del Valle do Brasil Ltda & \begin{tabular}{|ll} 
IP Desenvolvimento & Empresarial \\
Institucional $(*)$ & \\
\end{tabular} \\
\hline 52 Syngenta Proteção de Cultivo Ltda & John Deere Brasil S/A \\
\hline 54 Syngenta Seeds Ltda. & Justino de Morais Irmãos S/A - JUMIL $(*)$ \\
\hline 55 TV Globo Ltda & Lazzarini Moretti Sociedade de Advogados $(*)$ \\
\hline $\begin{array}{l}56 \text { União da Agroind. Canavieira de SP } \\
\text { (UNICA) }\end{array}$ & Malteria do Vale S/A \\
\hline 57 Usina Alto Alegre S/A. - Açúcar e Álcool & Máquinas Agrícolas Jacto S/A \\
\hline \multicolumn{2}{|l|}{58 Maubisa Agricultura S/A $(*)$} \\
\hline \multicolumn{2}{|l|}{59 Monsanto do Brasil Ltda. } \\
\hline \multicolumn{2}{|c|}{60 O Telhar Agropecuária Ltda. $(*)$} \\
\hline \multicolumn{2}{|c|}{61 Organização das Cooperativas Brasileiras (OCB) } \\
\hline \multicolumn{2}{|c|}{62 PricewaterhouseCoopers Auditores Independentes $(*)$} \\
\hline \multicolumn{2}{|c|}{63 Radar Propriedades Agrícolas S/A (*) } \\
\hline \multicolumn{2}{|c|}{64 Sindic. Nac. da Ind. Prod. Defesa Vegetal (Sindiveg) $\left(^{*}\right)$} \\
\hline \multicolumn{2}{|c|}{65 Sindic. Nac. da Ind. de Prod. Saúde Animal (Sindan) $(*)$} \\
\hline \multicolumn{2}{|c|}{66 SJ Brazil Agropecuária N. 1 Ltda. $(*)$} \\
\hline \multicolumn{2}{|l|}{67 SLC Agrícola S/A $(*)$} \\
\hline \multicolumn{2}{|l|}{68 Sollus Gestora de Terras Ltda. $(*)$} \\
\hline 69 Syngenta & \\
\hline
\end{tabular}




\begin{tabular}{|l|}
\hline 70 Tiba Agro $\left(^{*}\right)$ \\
\hline 71 União da Indústria de Cana-de-Açúcar (UNICA) \\
\hline 72 União dos Produtores de Bioenergia (UDOP) $\left(^{*}\right)$ \\
\hline 73 Usina Alto Alegre S/A - Açúcar e Álcool \\
\hline 74 Vanguarda Agro S/A $\left(^{*}\right)$ \\
\hline
\end{tabular}

Fontes: www.abag.org (acesso 20/11/2003 e 10-04-2014) e Caderno ABAG 20 anos, 2013.

LEGENDA:

NEGRITO - associados que permaneceram

ITÁLICO - associados que desapareceram

$(*)$ - novos associados

Alguns aspectos importantes se destacam da observação do Quadro 1. Em primeiro lugar, o expressivo aumento do número de associados da entidade representando, em termos percentuais, um crescimento de 130\%. Em segundo, a duplicação do número de integrantes ligados ao capital financeiro, que passou de quatro (2003) para oito (2013) empresas. Ao mesmo tempo, caso se agregue a este total os sócios vinculados a atividades comerciais e de "consultoria", este total se eleva de nove para dezenove membros, implicando num crescimento aproximado de $212 \%$, revelando a crescente financeirização da agremiação. Em terceiro lugar, dois outros pontos chamam nossa atenção no Quadro: a presença de firmas advocatícias e de empresas vinculadas a negócios com a terra, ambas as categorias ausentes do quadro de associados vigente em $2003^{3}$. Esses aspectos podem apontar para duas questões: a) o envolvimento da ABAG em causas, processos e/ou litígios que demandem apoio jurídico, como os casos envolvendo a biossegurança e crimes ambientais variados e b) a necessidade da ABAG estender seus tentáculos diretamente ao mercado de terras, interferindo junto a conflitos por sua posse e/ou estabelecendo uma espécie de "banco" de terras como reserva de valor para os empreendimentos setoriais em seu conjunto. $\mathrm{O}$ quarto ponto diz respeito à manutenção de cooperativas junto aos agremiados da entidade, a despeito do declínio em seu número no ano de 2013, que caíra do total de oito (2003) para seis, conquanto assegurando-se a permanência econômica e politicamente estratégica - da própria "instituição-mãe", a OCB. Cabe ainda destacar que as cooperativas remanescentes em 2013 transformaramse, quase todas, em cooperativas agroindustriais, enquanto em 2003 tratavam-se de cooperativas agropecuárias.

Por fim, num breve balanço geral dos dados fornecidos pelo Quadro 1, constata-se que, tanto em 2003 quanto em 2013, a ABAG caracterizou-se pela

\footnotetext{
Esses seriam os casos da Demarest \& Almeida Advogados, Lazzarini Moretti Sociedade de Advogados e PricewaterhouseCoopers Auditores Independentes e da Brasilagro Cia Brasileira de Propriedades Agrícolas, Radar Propriedades Agrícolas S.A. e Sollus Gestora de Terras Ltda.
} 
grande diversidade dos tipos de instituição dela participantes, abrigando desde empresas ligadas à produção e aperfeiçoamento de sementes - incluindo-se a pesquisa genética como a Monsanto ou a Bayer -, até aquelas vinculadas à mídia - como a Globo. Simultaneamente importa destacar o surgimento de 42 novos participantes da entidade em 2013 (i. e, renovando-se 57\% dos filiados); a permanência de apenas $32(43 \%)$ dos agremiados em ambos os anos e o desaparecimento de 25 empresas (33,8\%), constantes apenas da listagem de 2003, o que pode sugerir tanto processos de fusão/concentração empresarial, quanto alterações na razão social e/ou do âmbito de atuação de antigos membros ${ }^{4}$, abrindo-se uma nova trilha de questionamentos a serem investigados com o aprofundamento da pesquisa.

Logo, conquanto teoricamente definida como instância de articulação política de "agremiações patronais" do agronegócio, a ABAG desnuda-se, de fato, como um pool de grandes empresas, muitas delas estrangeiras e produtoras de tecnologia agrícola de ponta, com limitada participação de associações corporativas. Em 2013, quando do $20^{\circ}$ aniversário da entidade, ratificou-se, o predomínio das grandes empresas alimentadoras do agronegócio, em boa parte transnacionais, mormente aquelas ligadas ao setor químico como a Monsanto, a AGCO do Brasil; da Bayer S.A.; a DuPont do Brasil S.A.; a FMC ou a John Deere do Brasil S.A., dentre outras. Igualmente ilustrativa da abrangência das atividades dos membros da ABAG é a presença de empresas públicas junto a seus quadros, com destaque para a estatal Embrapa que, além de membro, executa pesquisas de ponta em parceria com outros sócios da Associação, que chegaram a integrar Diretorias Setoriais da própria empresa "pública” (MENDONÇA, 2011).

\section{A ABAG: REPRESENTATIVIDADE E AFIRMAÇÃO HEGEMÔNICA}

A despeito de ter-se imposto como força social hegemônica junto à sociedade civil como um todo, o coroamento da hegemonia da ABAG somente se completaria se conseguisse inscrever, junto à materialidade do Estado restrito ou sociedade política (GRAMSCI, op. cit., v. 3) seus próprios dirigentes, de modo a integrar a totalidade representada pelo binômio coerção-consenso, inerente ao Estado Ampliado capitalista ocidental (BIANCHI, 2008).

\footnotetext{
4 A Syngenta Seeds Ltda. resultou da fusão entre a Syngenta Proteção de Cultivo Ltda e a Syngenta Seeds Ltda; a Cocamar, em 2010, arrendou 24 unidades de negócios da Carol; a Maeda S/A, formou, junto a outras empresas, em 2011, a Vanguarda-Agro (V-Agro); a Pioneer Sementes foi incorporada a Du Pont Brasil; Sadia S.A. juntou ações com a Perdigão S.A. em 2009, integrando o Grupo Brasil Foods, BRF, por exemplo.
} 
Logo, nosso objetivo nesta seção do trabalho, é verificar em que medida processou-se a inscrição do projeto veiculado pela $\mathrm{ABAG}$ junto a agencias do Estado restrito, mormente aquelas afetas à definição e implementação de políticas econômicas em geral e agrícolas/agroindustriais em particular. Embora seja difícil acompanhar a configuração dos quadros dirigentes da agremiação desde seu início - posto que a documentação pesquisada apenas remeta, sintomaticamente, ao ano de 2003 quando da posse de Roberto Rodrigues como Ministro da Agricultura no governo Lula - tentaremos, mesmo com lacunas, recuperar essa trajetória. Para dar início a esse percurso, elaboramos o Quadro 2, que contempla os dirigentes da ABAG.

O primeiro aspecto revelado pelo Quadro 2 é o "perfil de carreira" seguido pelos presidentes da agremiação, uma vez que todos eles - à exceção de Luiz Alberto Garcia - ocuparam, previamente, algum posto na diretoria ou vice-presidência. Outra característica é a longevidade dos mandatos de certos dirigentes, como por exemplo, César Borges de Sousa (diretor e vice-presidente entre 1999 e 2013), Luis Antonio Pinazza (diretor técnico de 2002 até o presente) ou mesmo Carlo Lovatelli (presidente da ABAG de 2003 a 2012) e Luiz Carlos Corrêa Carvalho (diretor e vice-presidente entre 1999 e 2011, quando assumiu a titularidade). É digno de nota o crescimento do número de Diretores da ABAG, que passou de um total de oito em 1996, para doze em 2012.

Todavia, o coroamento da hegemonia da ABAG somente verificou-se com a expressiva inserção de seus representantes junto a agencias estratégicas da sociedade política. Para verificá-lo, elaboramos o Quadro 3.

O ponto axial do Quadro 3 - a despeito das lacunas existentes - é a participação concentrada de representantes da ABAG junto a variadas agencias do MAPA (Ministério da Agricultura, Pecuária e Abastecimento) em particular, junto às Câmaras Setoriais e Temáticas que compõem o Conselho do Agronegócio (CONSAGRO). Embora tenhamos localizado dados junto a apenas oito agências, cremos ter uma amostragem significativa da atuação dos intelectuais orgânicos / dirigentes da Associação junto ao Estado Restrito brasileiro.

Vale também destacar que se compõe boa parte dos membros da ABAG presentes nas Câmaras de dirigentes de alto escalão da entidade, quando não, de seus próprios presidentes, como nos casos de Luiz Antonio Pinazza - diretor técnico da agremiação entre 2003-2013 e membro de quatro das oito câmaras selecionadas e de Carlo Lovatelli, presidente da ABAG entre 2002 e 2012 que, igualmente, presidiu três câmaras setoriais no período de 2004 a 2011. 


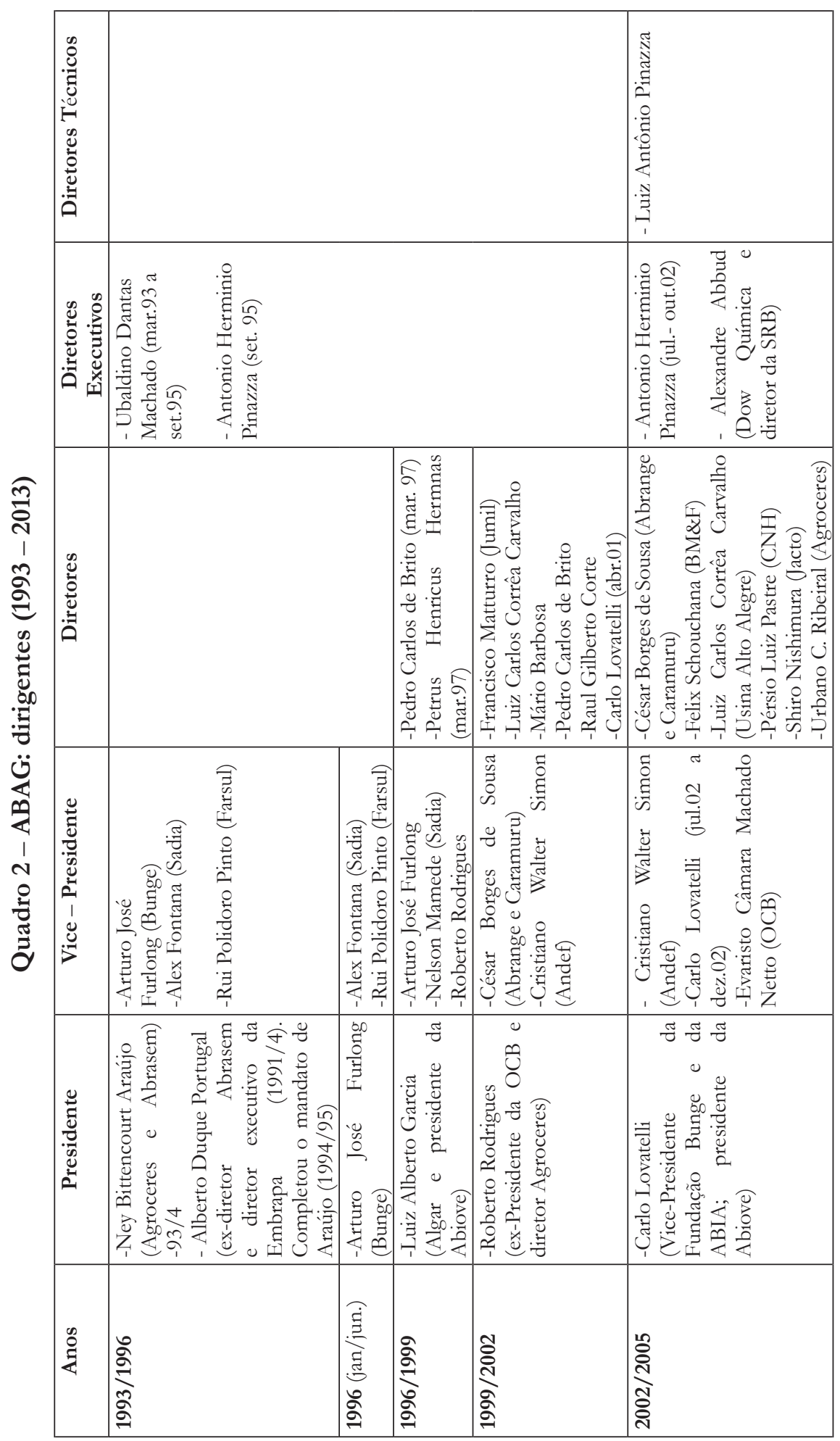


Quadro 3 - A ABAG em alguns órgãos da sociedade política (1991-2014)

\begin{tabular}{|c|c|c|}
\hline ÓRGÃOS & PERÍODO & REPRESENTANTE \\
\hline \multicolumn{3}{|c|}{ MAPA - Ministério da Agricultura, Pecuária e Abastecimento } \\
\hline 1.Secretaria de Política Agrícola & $2009-2011$ & $\begin{array}{l}\text { José Carlos Vaz }- \text { ex-Diretor de } \\
\text { Agronegócios do BB; dirigente da OCB } \\
\text { e dirigente da OCB }\end{array}$ \\
\hline 2 Secretaria Executiva & $2011-2013$ & $\begin{array}{l}\text { José Carlos Vaz }- \text { ex-Diretor de } \\
\text { Agronegócios do BB e ex-Secretário } \\
\text { de Política Agrícola no Ministério da } \\
\text { Agricultura; dirigente da OCB }\end{array}$ \\
\hline $\begin{array}{l}3 \text { Consagro - Conselho do Agronegócio } \\
\text { (criado 1998) }\end{array}$ & $\begin{array}{l}2003-2004 \\
2009-2011\end{array}$ & $\begin{array}{l}\text { OCB (Organização das Cooperativas } \\
\text { Brasileiras); CONTAG; ABAG; BM\&F } \\
\text { (Bolsa de Mercadorias e Futuros); SRB } \\
\text { (Sociedade Rural Brasileira). } \\
\text { OCB (Organização das Cooperativas } \\
\text { Brasileiras); BM\&F (Bolsa de Mercadorias } \\
\text { e Futuros); SRB (Sociedade Rural } \\
\text { Brasileira); ABAG (Associação Brasileira de } \\
\text { Agribusiness). }\end{array}$ \\
\hline $\begin{array}{l}\text { 3.1 Câmara Setorial da Cadeia Produtiva do } \\
\text { Milho e Sorgo }\end{array}$ & $2004-2008$ & $\begin{array}{l}\text { Presidente: César Borges (diretor da ABAG } \\
\text { desde 2006); Suplente - Luiz Antonio } \\
\text { Pinazza (Diretor Técnico da ABAG, 2003- } \\
\text { 2013) }\end{array}$ \\
\hline $\begin{array}{l}\text { 3.2 Câmara Setorial da Cadeia Produtiva da } \\
\text { Citricultura }\end{array}$ & $2004-2008$ & $\begin{array}{l}\text { Presidente - Monica Bergamaschi (Diretora } \\
\text { da ABAG, } 2003 \text { - 2011) }\end{array}$ \\
\hline $\begin{array}{l}\text { 3.3 Câmara Setorial da Cadeia Produtiva do } \\
\text { Açúcar e do Álcool }\end{array}$ & $2003-2008$ & $\begin{array}{l}\text { Presidente: Luiz Carlos Corrêa Carvalho } \\
\text { (presidente da ABAG desde 2012) }\end{array}$ \\
\hline $\begin{array}{l}\text { 3.4 Câmara Setorial da Cadeia Produtiva de } \\
\text { Oleaginosas e Biodiesel }\end{array}$ & $2004-2008$ & $\begin{array}{l}\text { Presidente: Carlo Lovatelli (presidente da } \\
\text { ABAG, 2002 -2012). } \\
\text { Suplente: Luiz Antonio Pinazza (Diretor } \\
\text { Técnico da ABAG, 2003-2013) }\end{array}$ \\
\hline $\begin{array}{llll}3.5 \quad \text { Câmara } & \text { Temática } & \text { de } & \text { Insumos } \\
\text { Agropecuários } & & & \\
\end{array}$ & $\begin{array}{c}2007-2010 \\
2011-13 \\
2014-.\end{array}$ & $\begin{array}{l}\text { Presidente - Cristiano Walter Simon } \\
\text { (consultor institucional da Andef e } \\
\text { Vice-presidente da ABAG (2003-2011); } \\
\text { Suplente- Luiz Antonio Pinazza (Diretor } \\
\text { Técnico da ABAG, 2003-2013) } \\
\text { Presidente - Luiz Antonio Pinazza } \\
\text { (Diretor Técnico da ABAG, 2003-2013); } \\
\text { Conselheiro - Carlo Lovatelli (presidente } \\
\text { da ABAG de 2002 -2012) } \\
\text { Presidente - Carlo Lovatelli (presidente da } \\
\text { ABAG, 2002 a 2012) }\end{array}$ \\
\hline $\begin{array}{l}\text { 3.6 Câmara Temática de Negociação Agrícola } \\
\text { Internacional consagro }\end{array}$ & $2004-2008$ & $\begin{array}{l}\text { Presidente: Monica Bergamaschi (diretora } \\
\text { da ABAG, } 2003 \text { a 2011); } \\
\text { Suplente: Alexandre Abbud (diretor } \\
\text { executivo da ABAG, } 2003 \text { a 2008) }\end{array}$ \\
\hline $\begin{array}{l}\text { 3.7 Câmara Temática de Financiamento e } \\
\text { Seguro do Agronegócio }\end{array}$ & 2004-2008 & $\begin{array}{l}\text { Presidente: Luiz Antonio Pinazza (Diretor } \\
\text { Técnico da ABAG, 2003-2013). }\end{array}$ \\
\hline $\begin{array}{l}\text { 3.8 Câmara Temática Infraestrutura e } \\
\text { Logística }\end{array}$ & $2004-2008$ & $\begin{array}{l}\text { Presidente: Carlo Lovatelli (presidente da } \\
\text { Abiove e da ABAG, } 2002 \text { - 2012) } \\
\text { Suplente: Alexandre Abbud (diretor } \\
\text { executivo da ABAG, } 2003 \text { a 2008) }\end{array}$ \\
\hline 4 EMBRAPA & 1991-1994 & $\begin{array}{l}\text { Diretor Executivo: Alberto Duque } \\
\text { Portugal (ex-Diretor da ABRASEM e } \mathbf{1}^{\circ} \text {. } \\
\text { Presidente da ABAG após a morte de Ney } \\
\text { Bittencourt Araújo }\end{array}$ \\
\hline
\end{tabular}




\begin{tabular}{|c|c|c|}
\hline \multicolumn{3}{|c|}{ MDIC - Ministério do Desenvolvimento, Indústria e Comércio Exterior } \\
\hline 1. CAMEX - Câmara do Comércio Exterior & $2010-2012$ & $\begin{array}{l}\text { Conselheiros : Marcos Jank (presidente da } \\
\text { UNICA) } \\
\text { Roberto Rodrigues - ex-presidente } \\
\text { da ABAG (1999-2002); ex-Ministro da } \\
\text { Agricultura (2003-2005) } \\
\text { Mário Fioretti - presidente da AGCO e } \\
\text { Diretor da ABAG (2011-2003) }\end{array}$ \\
\hline $\begin{array}{l}\text { 2. CONSEA - Conselho Nacional de } \\
\text { Segurança Alimentar e Nutricional (criado } \\
\underline{2003} \text { ) }\end{array}$ & $\begin{array}{l}2004-2006 \\
2007-2011\end{array}$ & $\begin{array}{l}\text { Presidente: Francisco Antonio da Fonseca } \\
\text { Menezes (diretor do IBASE) } \\
\text { Presidente: Fábio Meirelles (presidente da } \\
\text { CNA) } \\
\text { - Suplente: - Luiz Antonio Pinazza (Diretor } \\
\text { Técnico da ABAG, 2003-2013) }\end{array}$ \\
\hline $\begin{array}{l}\text { 3. CNPA - Conselho Nacional de Política } \\
\text { Agrícola }\end{array}$ & $2011-2014$ & ABAG \\
\hline $\begin{array}{l}\text { SECRETARIA DE AGRICULTURA DE } \\
\text { SP } \\
\text { CODEAGRO - Coordenadoria de } \\
\text { Desenvolvimento dos Agronegócios } \\
\text { (Secretaria de Agricultura do Estado de São } \\
\text { Paulo) }\end{array}$ & $2011-2013$ & $\begin{array}{l}\text { Embrapa; Mônika Bergamaschi } \\
\text { (Diretora ABAG, 2006-2011) }\end{array}$ \\
\hline
\end{tabular}

Nas agências dos demais ministérios, a presença da ABAG igualmente pode ser atestada, muito embora as fontes apenas mencionem a empresa à qual se vincula cada um dos conselheiros. Foi a partir delas que inferimos a participação da Associação junto a organismos como o Conselho Nacional de Segurança Alimentar e Nutricional (CONSEA) e, sobretudo, o Conselho de Desenvolvimento Econômico e Social da própria Presidência da República. Neste último, essencial para a tomada de decisões sobre a política econômica nacional, localizamos nove dirigentes de empresas sócias da ABAG, das quais quatro são grupos financeiros e/ou bancários, demonstrando a preponderância desta fração do capital tanto junto à agremiação, quanto ao próprio Estado restrito. Outra associada da ABAG com destacada participação junto à sociedade política é a OCB, integrante de quatro dos organismos pesquisados: Secretaria de Política Agrícola, Secretaria Executiva e Consagro (MAPA), além do CNDES.

Não podemos, todavia, esquecer de mencionar que o fortalecimento da ABAG verificou-se, igualmente, no âmbito da própria sociedade civil, tendo ela participado de aparelhos de hegemonia como o Conselho Superior de Estudos Avançados e Conselho Superior do Agronegócio, ambos da FIESP e do Comitê Nacional de Agroenergia, criação conjunta da FIESP, ABAG, CNA, OCB, SRB e Força Sindical, dentre outros. 


\section{COMENTÁRIOS CONCLUSIVOS}

Cremos, diante do até aqui apresentado, ter evidenciado a afirmação da ABAG como força hegemônica nacional em função de dois aspectos. Em primeiro lugar, pela conquista de novos canais de representação política setorial junto ao Estado Restrito, capacitando-a a interferir junto às políticas econômicas dele emanadas. Em segundo lugar, pelo fato da ABAG ter conseguido "absorver" e "neutralizar" dois processos contraditórios: o da progressiva fusão e concentração de empresas e capitais ligados a atividades concorrentes e o da gestão política das tensões daí advindas, instituindo-se em espaço de neutralização dos conflitos intraclasse dominante, mormente aqueles derivados da crescente financeirização do agronegócio.

\section{REFERÊNCIAS}

Caderno ABAG 20 anos. Brasília, 2013. Disponível em: http://www.abag. com.br/pdf/Caderno-20-anos.pdf. Acesso em: 12 mar. 2014. 76 p.

ARAÚJO, N. B. ABAG - Sugestões da ABAG para o presidente eleito, Dr. Fernando Henrique Cardoso. São Paulo, s/ed, 1994. 29 p.

ARAÚJO, N. B.; PINAZZA, L. A. Agricultura na Virada do Século XX - Visão de Agribusiness. São Paulo: Globo, 1994. 166 p.

ARAÚJO, N. B.; WEDEKIN, I.; PINAZZA, L. A. (orgs.). Agribusiness: o Complexo Agroindustrial Brasileiro. São Paulo: Agroceres, 1990. 238 p.

BIANCHI, A. O Laboratório de Gramsci. São Paulo: Alameda, 2008. 317 p.

BOURDIEU, P. O Poder Simbólico. Lisboa; Rio de Janeiro: Difel; Bertrand Brasil, 1989. 311p.

CORREIO BRAZILIENSE. Brasília: 1991 - 93.

GRAMSCI, A. Cadernos do cárcere. Rio de Janeiro: Civilização Brasileira, 2000. v. 3, 428p.

INFORMATIVO OCB. Brasília: Organização das Cooperativas Brasileiras, 1991.

MENDONÇA, S. R. de. Estado, pesquisa agropecuária e extensão rural no Brasil (1944 - 2005). Niterói: Relatório Final de Pesquisa ao CNPq, mar., 2011. 115 p.

O patronato rural no Brasil recente. Rio de Janeiro: UFRJ, 2010. 288 p.

. A industrialização brasileira. São Paulo: Moderna, 2004. 2. ed., 136 p.

O ESTADO DE SÃO PAULO. São Paulo: 1993. 